\title{
Correction to: The near repeats of gun violence using acoustic triangulation data
}

\author{
David M. Mazeika ${ }^{1} \cdot$ Lorena Uriarte $^{2}$
}

Published online: 14 March 2019

(c) Springer Nature Limited 2019

\section{Correction to: Secur J https://doi.org/10.1057/s41284-018-0154-1}

Due to an unfortunate oversight an error occured in the sentence "A Bookings Institution report by Carr and Doleac (2016) provides a more scientifically grounded non-reporting estimate of $12 \%$ of gunfire incidents."

The sentence should be read as follows:

"A Brookings Institution report by Carr and Doleac (2016) provides a more scientifically grounded reporting estimate of $12 \%$ of gunfire incidents."

Publisher's Note Springer Nature remains neutral with regard to jurisdictional claims in published maps and institutional affiliations.

The original article can be found online at https://doi.org/10.1057/s41284-018-0154-1.

David M. Mazeika

mazeikad@tcnj.edu

Lorena Uriarte

luriarte@ucpd.ucla.edu

1 Department of Criminology, The College of New Jersey, PO Box 7718, Ewing, NJ 08628-0718, USA

2 UCLA Police Department, 601 Westwood Pz, Los Angeles, CA 90095, USA

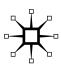

